\title{
Erratum to: Spatial resolution of FineCube, a newly developed cone-beam computed tomography system
}

\author{
Hiroshi Watanabe - T. Wagatsuma • \\ Y. Nomura • E. Honda · T. Kurabayashi
}

Published online: 18 March 2010

(C) Japanese Society for Oral and Maxillofacial Radiology and Springer 2010

\section{Erratum to: Oral Radiol}

DOI 10.1007/s11282-009-0032-y

We regret that there were some errors in the above-cited article.

1. In Fig. 2, the label for the $x$ axis, "Spatial frequency $(\mathrm{lp} / \mathrm{mm})$," should be "Spatial frequency $(\mathrm{lp} / \mathrm{cm})$ ".

2. In Table 2 , the units of spatial frequency " $\rho 50$ in $1 / \mathrm{mm}$ " and " $\rho 10$ in $1 / \mathrm{mm}$ " should be " $\rho 50$ in $1 / \mathrm{cm}$ " and " $\rho 10$ in $1 / \mathrm{cm}$," respectively.
3. In the second paragraph of "Discussion", in lines 7 and 8 , "26.8 $\mathrm{lp} / \mathrm{mm}$ " and " $22.8 \mathrm{lp} / \mathrm{mm}$ " should be "26.8 lp/cm" and "22.8 lp/cm," respectively.

We apologize for these errors and any confusion that they may have caused.

The online version of the original article can be found under doi:10.1007/s11282-009-0032-y.

H. Watanabe $(\bowtie) \cdot$ Y. Nomura $\cdot$ T. Kurabayashi

Oral and Maxillofacial Radiology, Division of Oral Restitution,

Graduate School, Tokyo Medical and Dental University,

5-45 Yushima 1-chome, Bunkyo-ku, Tokyo 1138549, Japan

e-mail: hiro.orad@tmd.ac.jp

T. Wagatsuma

Diagnostic Imaging Division,

The Yoshida Dental Mfg. Co., Ltd, Tokyo, Japan

E. Honda

Oral and Maxillofacial Radiology, Division of Oral Health

Sciences, The University of Tokushima Graduate School,

Tokushima, Japan 